\title{
Community composition, relative abundance and habitat association of avian species in Apini and Dikuma forest patches, Awi Administrative Zone, Ethiopia
}

\author{
Yenew Genet ${ }^{1}$ and Dessalegn Ejigu ${ }^{2 *}$ \\ ${ }^{1}$ Awi Adminstrative Zone Education Office, Injibara, Ethiopia; email: yenewg@yahoo.com \\ ${ }^{2}$ Department of Biology, Bahir Dar University, P.O. Box: 1817, Bahir Dar, Ethiopia
}

\begin{abstract}
Study on community composition, relative abundance and habitat association of avifauna in Apini and Dikuma forest patches, Awi Administrative Zone, Ethiopia, was carried out from September 2013 to April 2014. The main objective of this study was to investigate diversity, relative abundance, and habitat association of avian species in the study area. Data were collected using point count method, and analyzed using Shannon Weiner index, Simpson's diversity index and Sorensen's coefficient. A total of 95 avian species belonging to 44 families and 11 orders were identified. Among 95 bird species, 93 are residents, one is intra-African migrant and one is Palaearctic migrant, and of the 93 resident birds, seven are endemic to Ethiopia, and ten shared between Ethiopia and Eritrea. In the present study, 79 and 83 bird species were recorded during the wet and dry seasons, respectively. Dikuma forest patch had the highest avian diversity during the dry season $\left(\mathrm{H}^{\prime}=3.84\right)$ and Apini had the lowest $\left(\mathrm{H}^{\prime}=3.59\right)$ in the same season. Habitat association of birds among the vegetation strata showed the highest species similarity occurred between forest interior and forest edge $(\mathrm{CC}=0.65)$, followed by forest edge and shrub $(\mathrm{CC}=0.62)$, and the least was between forest interior and shrub $(\mathrm{CC}=0.3)$. Species richness and composition are important parameters to maintain stability and functioning of an ecosystem. To conserve the rich avian diversity of Apini and Dikuma forest patches, the anthropogenic disturbances in the area should be minimized.
\end{abstract}

Keywords: Diversity index, point count, relative abundance, resident birds, species similarity

DOI: http://dx.doi.org/10.4314/ejst.v10i1.3

\section{INTRODUCTION}

Ethiopia has diverse sets of ecosystems, ranging from humid forests and extensive wetlands to deserts and supporting a wide variety of life forms Ethiopian Wildlife and Natural History Society (EWNHS), 1996; Viveropol, 2001). The altitudinal difference with the highest peak of Ras Dashen (4543m a.s.1.) and the lowest in the Afar depression (120m below sea level) is the main reason for the highest biodiversity in Ethiopia (Shibru Tedela, 1995; EWNHS, 1996). These wide ranges of altitudes have given the country a variety of ecologically distinct and isolated areas that lead to the diversification of endemic species (EWNHS, 1996). According to Davies et al. (2007) variation in topography and temperature are the most important global predictors of avian species richness. Avian community composition, microhabitat selection, and guild assemblage can be affected by landscape features such as elevation, topography, proximity to water, forest patch size, distance between patches and the extents of forest edges (Hepinstall-Cymerman and Parrish, 2012).

Some birds have been classified as forest interior species due to their sensitivity to forest fragmentation, while others are referred to as

\footnotetext{
*Corresponding author: dessalegn_ejigu@yahoo.com

(C) This is an Open Access article distributed under the terms of the Creative Commons Attribution License (http://creativecommons.org/licenses/CC BY4.0).
} 
edge species because they are favoured by forest fragmentation (Angelstam, 1992). Habitat edges can affect species directly due to altered habitat characteristics and indirectly by facilitating movement or creating habitat for competitors, predators and parasites (Watson et al., 2004). Furthermore, the natural heterogeneity found in many parts of the forest structure such as abundance of large trees, dead wood and multilayered stands, canopy openness, the kinds and amounts of resources available for breeding and foraging activities can also affect avian communities (Naka and Cintra, 2012).

A study in the extremely fragmented and dry northern part of Ethiopia showed the occurrence of more species and a higher number of unique species in the forest patches than in open fields (Aerts et al., 2008). Therefore, understanding the effect of habitat disturbance on bird community structure is important to prioritize future conservation of biodiversity that are under great pressure either due to natural or human induced disturbances (Girma Mengesha et al., 2011).

In terms of avifauna, Ethiopia is one of the most significant countries in Africa, and the availability of different habitat types contribute for their diversity. Thus in Ethiopia, there are more than 857 avian species of which 20 are endemic, 29 are globally threatened and one introduced species (Lepage, 2014). A number of variables have been found to influence bird species diversity within a landscape. Some landscapes exhibit high richness in biological diversity than others. Mountain ecosystems are usually recognized as biodiversity hotspots harbouring rich biota often with high number of endemic species (Thapliyal et al., 2012). Much of the Ethiopian landscape is altered by agricultural activities, deforestation and over- grazing (Aerts et al., 2008). Habitat deterioration is particularly threatening quality of the ecosystems. Avian studies have great value to determine the importance of the site, habitat requirement of the species, and to understand the population dynamics (Gibbons et al., 1996). Seasonal variation in avian community structure decreases with increasing vegetation complexity (Symth, 1974; Karr, 1976). This is apparently due to the increased buffering of the physical environment by more complex vegetation.

Forests attract a large number of avifauna because of the habitat suitability for most of them (Hosetti and Harisha, 2009). These especially include the birds that are associated with the vegetation, and the existence of trees is vital to their life cycle. The Ethiopian highlands are particularly interesting as they comprise over $50 \%$ of the African land that is covered by Afro-montane vegetation (Tadesse Woldemariam et al., 2001). Most of the avian species occur in 73 Important Bird Areas (IBAs) (Shimelis Ayenalem and Afework Bekele, 2008). In Ethiopia, IBAs cover an area of about 47,757 $\mathrm{km}^{2}$, which is $5 \%$ of the country's total area. The extensive and unique conditions in the highlands of the country have contributed to the presence of a large number of endemic species.

Awi Adminstrative Zone, which has high elevation and diverse flora and fauna, is one of the IBAs in Ethiopia. The area harbours different species of birds some of which are not yet recorded and identified. Over the years, the avian diversity in this area is being affected by natural and anthropogenic threats leading to their local extinction. Hence, there is a need to study on species diversity, relative abundance, and their habitat association with different vegetation strata. The objective of this study was to investigate community 
composition, relative abundance, and habitat association of the avifauna in Apini and Dikuma forest patches of Awi Admistrative Zone in order to design appropriate conservation strategies.

\section{MATERIALS AND METHODS}

\section{Description of the study area}

The present study was conducted in two forest patches of Awi Administrative Zone, namely Apini and Dikuma forest patches, which are located North and South of Kidamaja town, respectively, $33 \mathrm{~km}$ away from Injibara town, and $380 \mathrm{~km}$ northwest of Addis Ababa. Apini forest patch lies between UTM 0246480 to $0249034 \mathrm{E}$ and 1218792 to $1221380 \mathrm{~N}$, with altitude of $2031 \mathrm{~m}$ a.s.l., and Dikuma lies between UTM 0242078 to 0246110 E and 1212354 to $1216692 \mathrm{~N}$, with altitude of 2040 $\mathrm{m}$ a.s.1. (Figure.1).

The area is known with hills and undulating mountains and gentle to slightly steep slopes. It is characterized by moist Afro-montane forests with different vegetation strata including trees, shrubs and grasses. Some of the dominant tree species include Cordia africana, Croton macrostachyus, Olea sepecies, Rosa abyssinica, Acacia abyssinica, Albizia species, Apodytes dimidiate, Ekebergia capensis, Ficus vasta, Prunus africana, Schefflera abyssinica, Rhus glutinosa, Pittosporum viridiflorum, Buddleja polystachya (Mark, 2002).

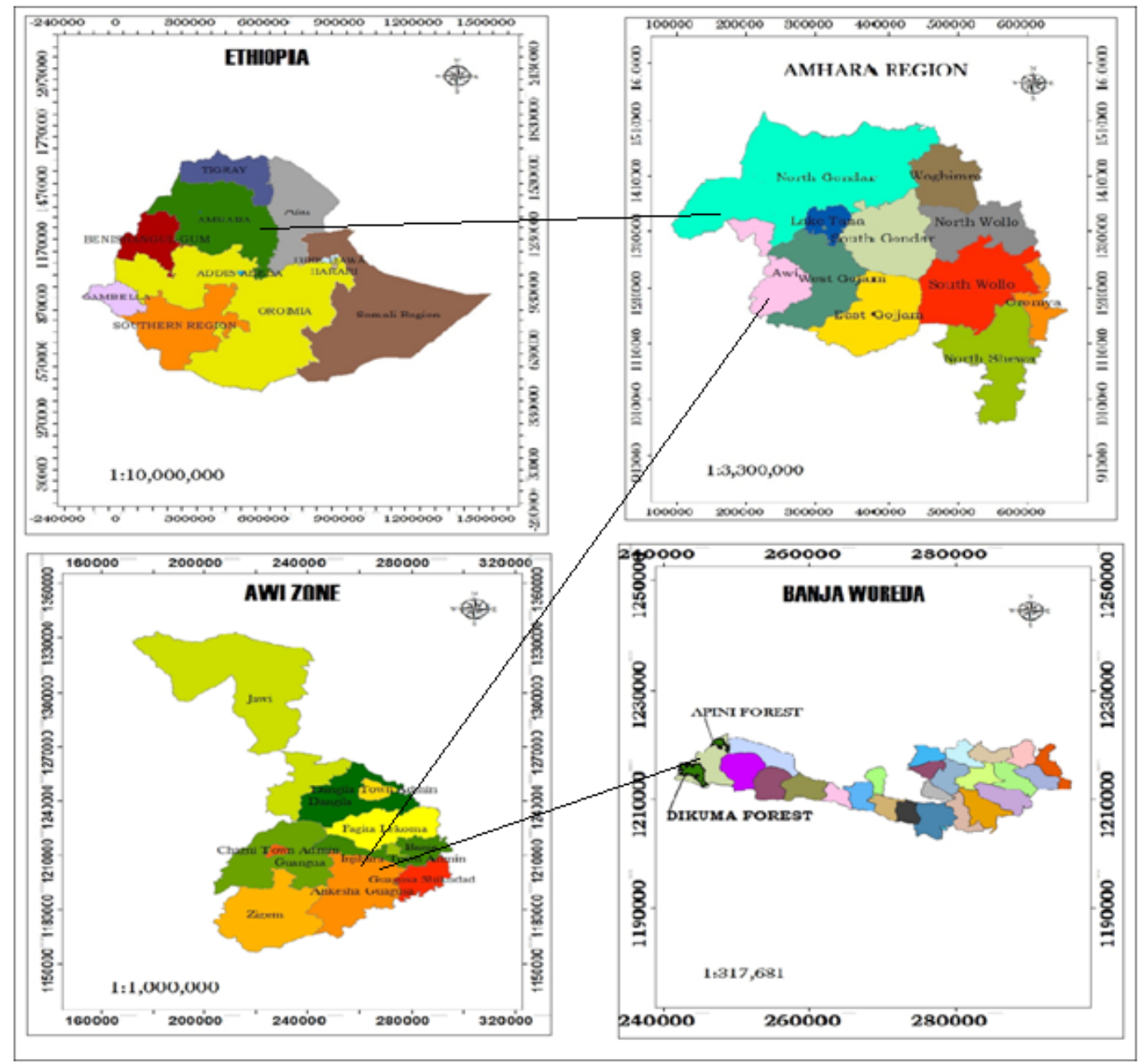

Figure 1. Location map of the study area 
The rainfall distribution in the study area is unimodal with heavy rainfall from June to September. The highest intensity of rainfall occurs in August with $358.9 \mathrm{~mm}$ and the lowest was in February with $1.5 \mathrm{~mm}$. Total amount of annual rainfall in the area varies between 1494.1-1907.3mm per year. The average annual minimum and maximum temperatures records were $9.3^{\circ} \mathrm{C}$ in January and $33.4^{\circ} \mathrm{C}$ in March, respectively.

\section{Methods}

A reconnaissance survey was carried out in August 2013 and during this survey, an overview of the avifauna of the study area was observed, and topographical features and vegetation structure were assessed. Additional information about the area was gathered from the local people living around the forest patches. Global Positioning System (GPS) readings were used to record the locations and to identify the altitudinal ranges of the study sites.

Based on the vegetation structure, the habitats of the study area were grouped into forest interiors, shrubs and forest edges. Sampling units representing each habitat types were selected based on stratified random sampling method. The technique involved dividing the study area into blocks by choosing the location of each habitat with random numbers (Sutherland, 1996). Thus, eight sample blocks were selected at random to be representative of the whole study area.

Point count method was used to record the presence or abundance of bird species (Bibby et al., 2000; Buckland et al., 2001). Censuses were taken on 32 sampling points of which 12 were from forest interiors, 8 from shrubs, and 12 from forest edges. In each point count station, a minimum distance of 150 - 200m was maintained using GPS to avoid double counting (Vielliard, 2000). To minimize disturbance during census, waiting period of 3-5minutes prior to counting individuals of avian species was maintained (Hosteler and Martin, 2001). Point count duration was 5-15minutes interval depending up on the difficulties of the area and the type of bird species to be identified and enumerated (Vielliard, 2000). All birds seen and heard from $25 \mathrm{~m}$ radius were recorded. The survey was conducted along a series of point counting stations by counting the number of birds detected on each point counting station (Buckland, 2006). A total of six visits i.e. three during the wet season and three during the dry season were carried out, and in each visit and in each site, data were collected for five consecutive days.

Wet season data were collected during September to November 2013, while data for the dry season were collected during February to April 2014. Data were collected from 6:30 a.m. to 10:00 a.m. in the morning and from 3:00 p.m. to 6:00 p.m. in the afternoon when bird activity was maximum and on days with good weather conditions (Centerbury et al., 2000). The sequence, in which stations visited was in alternative ways (i.e., point stations observed in the morning for the first day was observed in the afternoon in the second day and vice-versa) among sampling periods to partially compensate for effects of hourly variation in bird activity (Rodriguez-Ferraro and Blake, 2008), and counting stations for each forest sites were completed in one day to make them as comparable as possible.

Avian identification was based on different morphological features such as plumage pattern, size, shape, colour and calls (Redman et al., 2009), and using field guides (Stevenson and Fanshawe, 2002; Redman et al., 2009), and observations were assisted by binoculars. 


\section{Data analysis}

Birds' species diversity was analyzed using Shannon-Wiener Diversity Index $\left(\mathrm{H}^{\prime}\right)$. Simpson's Index of Diversity (D) was used to evaluate the relative abundance of avian species in each habitat type. Evenness (E) was used to quantify the unique representation of a species against a given hypothetical community in which all species are equally common (Krebs, 1999). Relative abundance of avian species was determined using encounter rates following Bibby et al. (1998).

Encounter rate was calculated for each species by dividing the number of birds recorded by the number of hours spent searching, in order to get number of individuals per hour for each species. Abundance categories were $<0.1,0.1-2.0,2.1$ - 10.0, 10.1- 40.0 and $40^{+}$. For each category, the following abundance score was given 1 (rare), 2 (uncommon), 3 (frequent), 4 (common), and 5 (abundant). The community similarity of bird species of the two forest patches was assessed using Sorensen's coefficient as adopted from Jeffery et al. (2004) as $\mathbf{C C}=2 \mathrm{C} / \mathbf{A}+\mathbf{B}$; where $\mathrm{CC}$ $=$ Sorensen's coefficient; $\mathrm{A}=$ number of species that occur in site $\mathrm{A} ; \mathrm{B}=$ number of species that occur in site $\mathrm{B} ; \mathrm{C}=$ number of common species that occur in site A and site B. Community similarity among the three habitat types within the study sites was analyzed as $\mathbf{C C}=3 \mathrm{D} / \mathbf{A}+\mathbf{B}+\mathbf{C}$; where $\mathrm{A}, \mathrm{B}$, and $\mathrm{C}$ are number of species that occur in habitat $\mathrm{A}$, habitat $\mathrm{B}$, and habitat $\mathrm{C}$, respectively, and $\mathrm{D}$ is number of common species that occur in the three habitat types of each sites.

\section{RESULTS}

A total of 95 bird species belonging to 11 orders and 44 families were identified during the present study with 79 and 83 species during the wet and the dry seasons, respectively. Among them 67 species were common for both seasons, 12 species were recorded only during the wet season, and 16 species only during the dry season. The highest number of species was recorded for the families Ploceidae, Accipitridae, and Columbidae, which were followed by Sturnidae, Turdidae, Muscicapidae and Corvidae. Order Passeriformes contained the highest number of families (29) and species (62). Among the 95 bird species, 93 are residents, one is intra-African migrant and one is Palaearctic migrant.

Seven of the total species identified namely yellowfronted parrot (Poicephalus flaviforns), black winged love bird (Agaporni staranta), Abyssinian long claw (Macronyx flavicollis), Abyssinian catbird (Parophasma galinieri), African hill-babbler (Pseudoalcippe abyssinica), Abyssinian ground thrush (Zoother apiaggiae), and Abyssinian crimson wing (Cryptospiza salvadorii) were endemic to Ethiopia.

\section{Species diversity}

The highest number of avian species was recorded in Dikuma forest patch both during the wet and dry seasons. The Shannon-Weiner diversity index revealed that more avian species diversity $\left(\mathrm{H}^{\prime}=3.84\right)$ was recorded in Dikuma during the dry season and the least $\left(\mathrm{H}^{\prime}=3.59\right)$ was recorded in Apini in the same season (Table 1). Avian species were evenly distributed in these areas as indicated by the evenness value $(\mathrm{E}=0.89)$.

\section{Distribution of avian species}

The three habitat types namely forest interiors, shrubs, and forest edges varied in the number of avian species diversity and abundance. During the wet and dry seasons, the highest number of species was recorded in the forest edges, followed by forest 
Table 1. Avian species diversity in the study area during the wet and dry seasons

\begin{tabular}{lllllll}
\hline \multirow{2}{*}{ Study area } & Season & $\begin{array}{l}\text { No. } \\
\text { species }\end{array}$ & $\begin{array}{l}\text { of } \\
\text { Ind ivid u a l } \\
\text { abundance }\end{array}$ & D & H' & E \\
\hline \multirow{4}{*}{ Apini } & Wet & 64 & 1956 & 0.97 & 3.66 & 0.88 \\
& Dry & 58 & 1698 & 0.96 & 3.59 & 0.88 \\
& Both seasons & 57 & 1804 & 0.97 & 3.61 & 0.89 \\
& & & & & & \\
\multirow{5}{*}{ Dikuma } & Wet & 67 & 2408 & 0.97 & 3.73 & 0.89 \\
& Dry & 77 & 2444 & 0.97 & 3.84 & 0.88 \\
& Both seasons & 61 & 2188 & 0.97 & 3.64 & 0.89 \\
\hline
\end{tabular}

Note: $\mathrm{D}=$ Simpson's Index of Diversity, $\mathrm{H}^{\prime}=$ Shannon-Weiner Index, E =Evenness

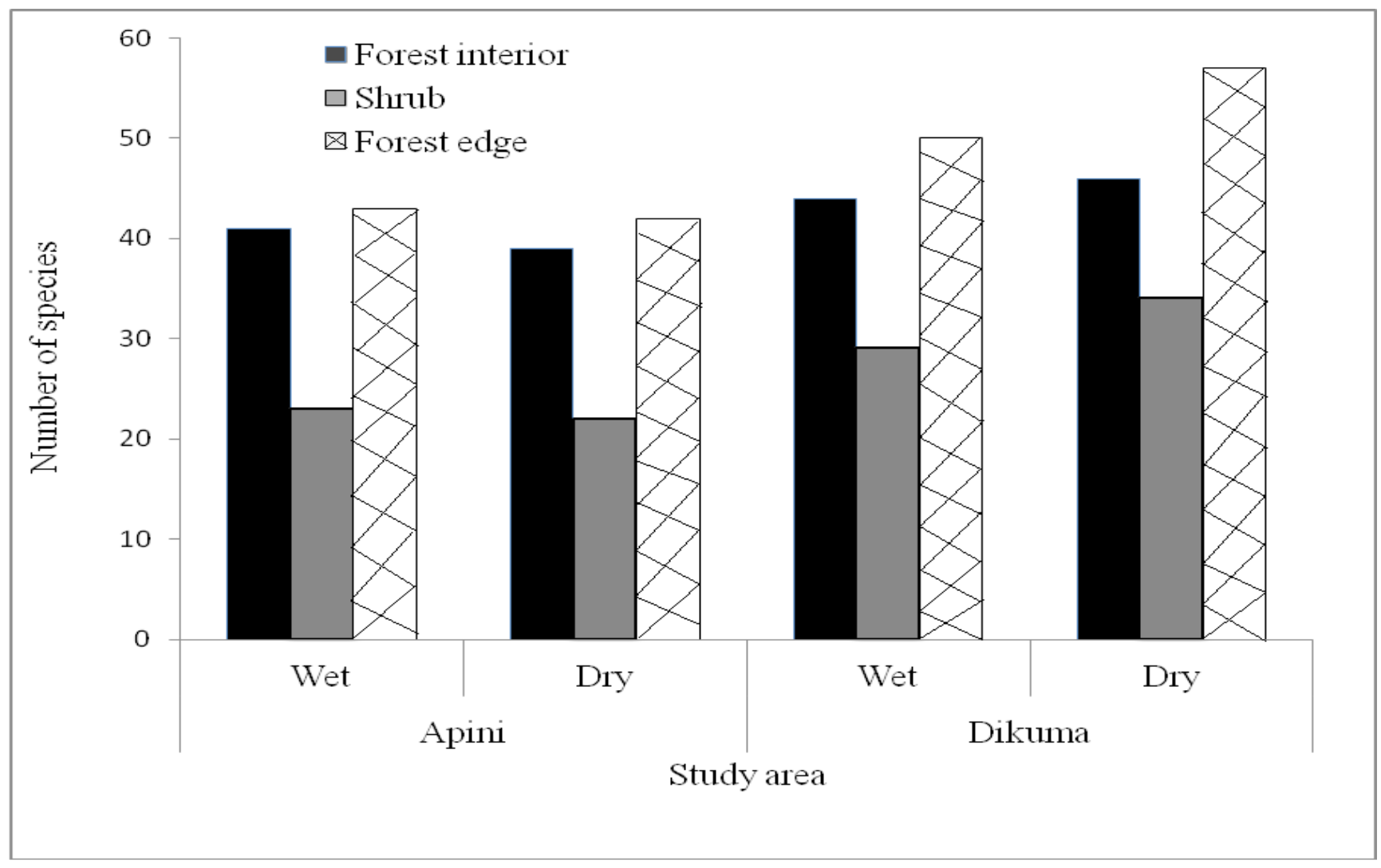

Figure 2. Avian species distribution among the three habitat types 
interior, and the lowest was observed in shrubs. Shrubs had less avian diversity than other habitats regardless of season and site. Apini, forest interior and forest edge did not show difference in bird species diversity (Figure 2).

\section{Relative abundance}

Relative abundance of avian fauna in the Apini and Dikuma forest patches during the wet and dry seasons indicated that $107(40.2 \%)$ of the individual birds encountered were frequent, 89(33.5\%) were uncommon, and 70(26.3\%) were common species. This indicated that there were more uncommon species in Apini during the wet season and frequent species in Dikuma during the dry season (Table 2).
Species similarity between the two forest patches indicated that the maximum value of seasonal species similarity was observed in Apini forest patch (Table 3).

Species similarity between the two forest patch communities were $\mathrm{CC}=0.77$ and $\mathrm{CC}=0.79$ in the dry and wet seasons, respectively. The overall community similarity of the two forest patches were $(\mathrm{CC}=0.73)$. Community similarity among the three habitat types during both the wet and dry seasons indicated that relatively high similarity was recorded between forest interior and forest edge $(\mathrm{CC}=0.65)$. Similarity between shrubs and forest edge was $(\mathrm{CC}=0.62)$, and the lowest species similarity was obtained between forest interior and shrubs $(\mathrm{CC}=0.3)$.

Table 2. Relative abundance of birds in the study area during the wet and dry seasons

\begin{tabular}{lllll}
\hline \multirow{2}{*}{ Study area } & Season & Uncommon species & Frequent species & Common species \\
\hline \multirow{2}{*}{ Apini } & Wet & 26 & 22 & 16 \\
& Dry & 22 & 20 & 16 \\
\multirow{2}{*}{ Dikuma } & Wet & 20 & 28 & 19 \\
& Dry & 21 & 37 & 19 \\
\hline
\end{tabular}

Table 3. Percentage of seasonal species similarity within the same forest type

\begin{tabular}{llllll}
\hline Study area & Season & & $\begin{array}{c}\text { Number } \\
\text { species }\end{array}$ & of & $\begin{array}{c}\text { common } \\
\text { Species similarity between }\end{array}$ \\
\hline & Wet & Dry & & $93.4 \%$ \\
Apini & 64 & 58 & 57 & $84.7 \%$ \\
Dikuma & 67 & 77 & 61 & \\
\hline
\end{tabular}




\section{DISCUSSION}

Apini and Dikuma forest patches have quite diverse flora, which harbour 95 species including seven endemic species of Ethiopia. Ten avian species such as African citril (Serinus citrinelloides), white winged cliff chat (Thamnolaea semirufa), Abyssinian oriole (Oriolus monacha), white backed black tit (Parus leuconotus), thick billed raven (Corvus crassirostris), white throated seed eater (Serinus xanthopygius), banded barbet (Lybius undatus), Abyssinian wood pecker (Dendropicos abyssinicus), wattled ibis (Bostrychia carunculata), and white collared pigeon (Columba albitoraues) are shared endemic species between Ethiopia and Eritrea. This coincides with the result of Teklu Gosaye (2011) as he reported that five endemic species of Ethiopia and seven endemic species shared with Eritrea in south west shoa, Ethiopia. In the present study, birds belonging to family Passeriformes are the most abundant which is in line with Kalkidan Esayas (2010), and Girma Mengesha et al. (2011) indicating that Passeriformes are the most diversified avian family in the country.

The abundance and diversity of bird species were the highest during the dry season in Dikuma forest patch. This might be due to an increased frequency of fruiting and flowering trees such as Schefflera abyssinica, Ficus vast, Prunus africana, Apodytes dimidiate in the area. Moreover, the presence of Jungi and Sahesahi forest patches in the nearby eastern and southwestern direction, respectively, with sufficient perennial rivers including Girdi River and Ardi River, and the presence of crop farm lands closer to the forest might have contributed to the presence of more avian species in Dikuma forest during the dry season.
Moreover, the presence of different plant composition in Dikuma forest patch supports the greater bird species since each plant species can support different avian communities. As reported by Nabaneeta and Gupta (2010) bird species richness and abundance are influenced by the size of habitat patches, local resource availability and vegetation composition. However, studies by Hansson (1997) indicated that the number of plant species was not clearly correlated with the number of bird species.

In the present study, avian species diversity and abundance were relatively highest at the forest edges as edges are more heterogeneous, which was followed by forest interiors, and the least record was in shrubs. This is because the number of avian species is strongly correlated to site areas but not to internal heterogeneity (Hansson, 1997). Hence, diversity and abundance of avian species were distributed differently among different microhabitats. This might relate with the idea that change in habitat characteristics could influences species diversity and their relative abundance.

Forest edge habitat had the highest diversity and abundance of birds. This might be due to the availability of enough food which attracts birds that feed on fruits and seeds, increase in light intensity, larger fluctuations in temperature and humidity. This is in line with the results of Laiolo and Rolando (2005), Aich and Mukhopadhyay (2008) who confirmed that forest edge has the greatest diversity and abundance of birds compared to forest interior and shrubs. However, Peake and Ritchison (1998) argued that high edge predation rate might force some species of birds to shift their nest towards places where sufficient cover to hide the nest is available in order to avoid predation. 
The forest interior is the second in species diversity and abundance, and the diverse micro-habitat such as tree density, fallen logs and standing dead trees might have great contribution. As the number of vegetation layer increases, the number of available niches also increases and so does the diversity of avian species. This is similar to a study by Greenberg and Langham (2001) who described that an abundance of arthropod foods, nesting materials, micro sites for nesting, and vegetative structure are the primary factors that attract breeding birds to the forest gaps.

The lowest abundance and diversity of species was observed in shrubs. This might be attributed to high human disturbance and livestock grazing in shrub habitats. This idea agrees with the report of Mahood et al. (2012) as shrubs are essential components of an anthropogenic and heavily disturbed matrix, which is usually less suitable for conservation of biodiversity. Intensive grazing of domestic livestock, primarily cattle is correlated with decreased structural complexity of forest vegetation, and this led to the decline and loss of a wide variety of avian species in shrub lands (Scott et al., 2003). Over grazing in the shrub habitat results in flushing of nests by rain due to the absence of hay material for nesting birds. Unavailability of hay causes exposure which allows the birds of prey to approach the eggs or chicks of breeding birds (Ali and Bibi, 2013).

The presence of more uncommon species of birds in Apini forest patch both during the wet and dry seasons might be due to the relatively large home range and niche of the species. Ryan and Owino (2006) suggested that the presence of large number of uncommon species in a certain area could be related to the breeding nature and large home range of the species. It is realized that some species of birds stay fluctuating in the same habitat both in the wet and dry seasons, and some others such as common fiscal (Lanius collaris), swainson's sparrow (Passer swainsonii) and red billed fire finch (Lagonosticata senegala) change their habitat, and use farmland when crops are on the field. During the post harvest period, they tend to concentrate to forest edges. This variation in abundance and occupancy over time was also observed even in species with a relatively stable population (Gaston et al., 2000).

Some of the most common species in the two forest patches were mountain thrush (Turdus abyssinicus), Abyssinian oriole (Oriolus monacha), Ethiopian boubou (Laniarius aethiopicus), common bulbul (Pycnonotus barbatus), greater blue-eared starling (Lamprotornis chalybaeus), scarlet chested sun bird (Chalcomitra senegalensis), Rueppell's robinchat (Cossyph asemirufa). The presence of nectar feeding insects, large branched fruiting trees and suitable weather conditions might have contributed to the occurrence of these species in the two study sites.

The insignificant seasonal difference in the diversity of bird species within the same forest type in the present study is in agreement with Symth (1974), Karr (1976), and Karr and Freemark (1993). This might be due to the presence of structurally complex vegetation types that buffer the effect of seasonality. There is also a greater stability in resource availability which allows species to occur as residents throughout the year. However, this idea disagrees with the work of Kalkidan Esayas (2010) and Teklu Gosaye (2011) as they observed additional avian species during the wet season. 
The Sorensen's coefficient showed that the overall community similarity of the two forest patches were relatively high $(C C=0.73)$. This indicated that bird habitat association of the two forest patches is nearly similar. Geographic proximity and similar climatic conditions between the two study sites might lead to the occurrence of similarities in bird community. Among the different habitat types, avian species similarity was higher between forest edge and forest interior. Tubelis and Cavaicanti (2001) noted that similarity of avian species composition between habitats indicates a tendency for similar habitats to have similar species composition. In contrast, the lowest avian species similarity was observed between forest interior and shrub. This is probably due to the differences in feeding adaptation of avian communities in each habitat. Aich and Mukhopadhyay (2008) described that canopy closure supports more of habitat specialist species, while areas under anthropogenic influence harbours more of opportunistic bird species.

\section{CONCLUSION AND}

\section{RECOMMENDATIONS}

The present study showed that Apini and Dikuma forest patches support diversified bird species belonging to different families and orders. Family Ploceidae, Columbidae, and Accipitridae are the most widely distributed families in the area. Seven endemic bird species of Ethiopia and ten endemic species shared with Eritrea are identified in the study area. Diversity and abundance of avian species are relatively higher at forest edges than forest interiors and shrubs. Regardless of various avian species and other faunas available in the present study area, the attention given to conserve its biota is not significant. Forests are managed for human uses primarily for livestock grazing and firewood rather than for biodiversity conservation. Therefore, habitat disturbance due to various anthropogenic activities have a prominent impact on the abundance and diversity of birds in the study area.

As the conservation effort in the area is minimal, the long term survivals of range- restricted birds are threatened by ongoing and expanding vegetation changes. Therefore, it is necessary to take appropriate conservation measures to mitigate the expansion of human interference before large scale destruction is made. Thus, to ensure the avifauna diversity and abundance in the area, the fuel wood demand of the local people should be replaced by alternative energy sources. Moreover, awareness creation of the local people and participatory conservation strategies should be practiced in order to conserve avian species in the area.

\section{ACKNOWLEDGEMENTS}

We would like to acknowledge the Department of Biology, Bahir Dar University, for lending us GPS during data collection. We greatly thank to Goshu Zewudie and Amera Moges for their prominent help in provision of additional field equipment required during the study period. We owe our appreciation to agricultural experts and the local people for their willingness and help in data collection. Moreover, the help rendered by Tsegaye Worku and Desse Tamer during data collection is highly acknowledged. 


\section{REFERENCES}

Aerts, R., Lerouge, F., November, E., Lens, L., Harmy, M and Muys, B. (2008). Land rehabilitation and the conservation of birds in a degraded Afromontane landscape in northern Ethiopia. Biodiversity and Conservation 17:53-69.

Aich, A and Mukhopadhyay, S.K. (2008). Comparison of avifauna at the edge of contrasting forest patches in western Ghat hills of India. Ring 30(1):5-14.

Ali, Z and Bibi, F. (2013). Measurement of diversity indices of avian communities at Taunsa Barrage Wildlife Sanctuary, Pakistan. Journal of Animal and Plant Science 23(2):469- 474.

Angelstam, P. (1992). Conservation of communities-the importance of edges,surroundings and landscape mosaic structure. In: Ecological Principles of Nature Conservation, pp. 9-70 (Hansson, L. eds.). Elsevier Applied Science, London.

Bibby, C.J., Johnes, M and Marsden, S. (1998).

Expedition Field Techniques. Bird Surveys. The expedition Advisory Center Royal Geographic Society, London.

Bibby, C.J., Burgess, N.D and Hill, D.A. (2000).

Bird Census Techniques.2 ${ }^{\text {nd }}$ ed. Academic Press, London.

Buckland, S.T. (2006). Point-transect surveys for song birds: Robust methodologies. $A U K$ 123:345-357.

Buckland, S.T, Anderson, D.R, Burnham. K.P, Laake. J.L and Borchers, D.L. (2001).

Introduction to Distance sampling: Estimating Abundance of Biological Populations. Oxford University Press, Oxford.
Centerbury, G.E., Martin, T.E., Petit, L.J and Bradford, D.F. (2000). Bird communities and habitats are ecological indicators of forest condition in regional monitoring. Conservation Biology 14:1-14.

Davies, R.G., Ormem C.D., Storch, D., Olson, V.A., Thomas, G.H., Ross, S.G., Dingm, J., Rasmussen, P.C., Bennett, P.M., Owens, I.P., Blackburn, J.M and Gaston, K.J. (2007).

Topography, energy and the global distribution of bird species richness. Proceedings of the Royal Society B. 274:1189-1197.

Ethiopian Wild life and Natural History society (EWNHS). (1996). Important Bird Areas of Ethiopia: A First Inventory. Ethiopian Wildlife and Natural History Society, Addis Ababa.

Gaston, K.J., Blackburn, T.M., Greenwoodx, J.D., Greroryx, R.D., Rachel, M.Q and Lawton, J.H. (2000). Abundance-occupancy relationships. Journal of Applied Ecology 37:39-59

Gibbons, D.W., Hill, D.A and Sutherland, W.J. (1996). Birds. In: Ecological Census Techniques: A Hand Book, pp 81-95 (Sutherland, W. J. eds.). Cambridge University Press, Cambridge.

Girma Mengesha,Yosef Mamo and Afework Bekele. (2011). A composition of terrestrial bird community structure in the undisturbed and disturbed areas of the Abijata Shalla Lakes National Park, Ethiopia. International Journal of Biodiversity and conservation 9: 389-404.

Greenberg, C.H and Langham. J.D. (2001). Breeding bird assemblages of hurricanecreated gaps and adjacent closed canopy forest in the southern Appalachians. Forest Ecology and Management 154:251-260. 
Hansson, L. (1997). Environmental determinants of plant and bird diversity in ancient oakhazel woodland in Sweden. Forest Ecology and Management 91:137-143.

Hepinstall-Cymerman, J and Parrish, C. M. (2012). Associations between multi-scale landscape characteristics and breeding bird abundance and diversity across urban-rural gradients in northeastern Georgia, USA. Urban Ecosystems 15:559-580.

Hosetti, B.B and Harisha, N.M. (2009). Diversity and distribution of avifauna of Lakkavalli range forest, Bhadra Wildlife Sanctuary, western Ghat, India. ECOPRINT 16:21-27.

Hosteler, M.E and Martin, M.B. (2001). Florida

Monitoring Program: Transect and Point Count Method for Surveying Birds. University of Florida.

Jeffery, C., Diane, M., Debinsi, O. Jakubausk, S and Kelly, K. (2004). Beyond species richness, community similarity as a measure of cross taxon congruence for coarse filter conservation. Conservation Biology 18:167173.

Karr, J.R. (1976). Seasonality, resource availability and community diversity in tropical bird communities. Nature 110:973-994.

Kalkidan Esayas (2010). Species composition, relative abundance and distribution of avian fauna of Entoto Natural Park and Escarpment. MSc.Thesis Addis Ababa University, Ethiopia.

Karr, J.R and Freemark K.E.(1993). Habitat selection and environmental gradients: dynamics in the "stable" tropics. Ecology 64:1481-1494.

Krebs, C. J. (1999). Ecological Methodology. $2^{\text {nd }}$ edn. Addison-Welsey Educational Publishers, Washington.
Laiolo, P and Rolando, A. (2005). Forest bird diversity and ski-runs: a case of negative edge effect. Animal Conservation 7:9-16.

Lepage. D. (2014). Avibase-bird check lists of the World-Ethiopia. http://www.bsc.eoc.org. (accessed on 16/02/2014).

Mahood, S.P, Lees, A.C and Peres, C. A. (2012). Amazonian country side habitats provide limited avian conservation value. Biodiversity Conservation 21:385-405.

Mark, M. (2002). Manual of Highland Ethiopian Trees and Shrubs. SIM Forestry study project Injbara Awi zone, Ethiopia. Banawee Printing Press.

Nabaneeta, A and Gupta, A.(2010). Avian community analysis in fragmented landscapes of Cachar District. Journal of Science Technology 5:75-84.

Naka, N.L and Cintra, R. (2012). Spatial variation in bird community composition in relation to topographic gradient and forest heterogeneity in a central Amazonian rainforest. International Journal of Ecology 11: 37- 43 .

Peake, D.R and Ritchison G. (1998). Nest site selection and nesting success in white-eyed vireos. Kentucky Warbler 74:64-67.

Redman, N., Stevenson, T and Fanshawe, J. (2009). Birds of the Horn of Africa. Ethiopia, Eritrea, Djibouti, Somalia and Socotra. Princeton University Press, Princeton and Oxford.

Rodriguez-Ferraro, A and Blake, J.G. (2008). Diversity patterns of bird assemblages in arid zones of Northern Venezuela. The Condor 110:405-420. 
Ryan, P.G and Owino, A.O. (2006). Habitat

Association of Papyrus Specialist Birds at Three Papyrus swamps in Western Kenya. Blackwell Publishing. Ltd. Nairobi.

Scott, M.L., Skagen, S.K., and Merigliano, M.F. (2003). Relating geomorphic change and grazing to avian communities in riparian forests. Conservation Biology 17(1):284-296.

Shibru Tedela (1995). Protected area management crisis in Ethiopia. Walia 16:17-30.

Shimelis Aynalem and Afewore Bekele. (2008). Species composition, relative abundance and distribution of bird fauna of riverine and wetland habitats of Infranz and Yiganda at southern tip of Lake Tana, Ethiopia. Tropical Ecology 49:199-209.

Stevenson, T and Fanshawe, J. (2002). Field

Guide to the Birds of East Africa: Kenya, Tanzania, Uganda, Rwanda and Burundi. Christopher Helm, London.

Sutherland, W.J. (1996). Ecological Census

Techniques. A Hand Book. Cambridge University Press, Cambridge.

Symth, N. (1974). Biological Monitoring Datainsect. Environmental Monitoring and Baseline Data. Smithsonian Institution Environmental Science Program, Washington, D.C.

Tadesse Woldemariam, Demel Teketay, Edwards, S. and Olsson, M. (2001). A comparative assessment of diversity and density of birds in Chilimo forest, Ethiopia. Ostrich Supplement 15:216-223.

Teklu, Gosaye. (2011). Avian diversity based on habitat difference at Geto and Gembejo areas, southwest shoa, Ethiopia. MSc. Thesis, Addis Ababa University.
Thapliyal, A., Bhatt, D and Joshi, K. (2012). Avian diversity and its association with vegetation structure in different elevational zones of Nainital district (Western Himalayan) of Uttarakhand. International Journal of Biodiversity and Conservation 4 (11): 364376.

Tubelis, D.P and Cavaicanti, R. B. (2001). Community similarity and abundance of bird species in open habitats of a central Brazilian cettado. Ornitologia Neotropical 12:57-73.

Vielliard, J.M.E. (2000). Bird community as an indicator of biodiversity: results from quantitative surveys in Brazil. Anais da Academia Brasileira de Ciencias 72:323-330.

Viveropol, L. J. (2001). A Guide to Endemic Birds of Ethiopia and Eritrea. Shama Books, Addis Ababa.

Watson, J.E, Whittaker, R J and Dawson TP. (2004). Habitat structure and proximity to forest edge affect the abundance and distribution of forest-dependent birds in tropical coastal forests of Southern Madagascar. Biological Conservation 120:311-327. 


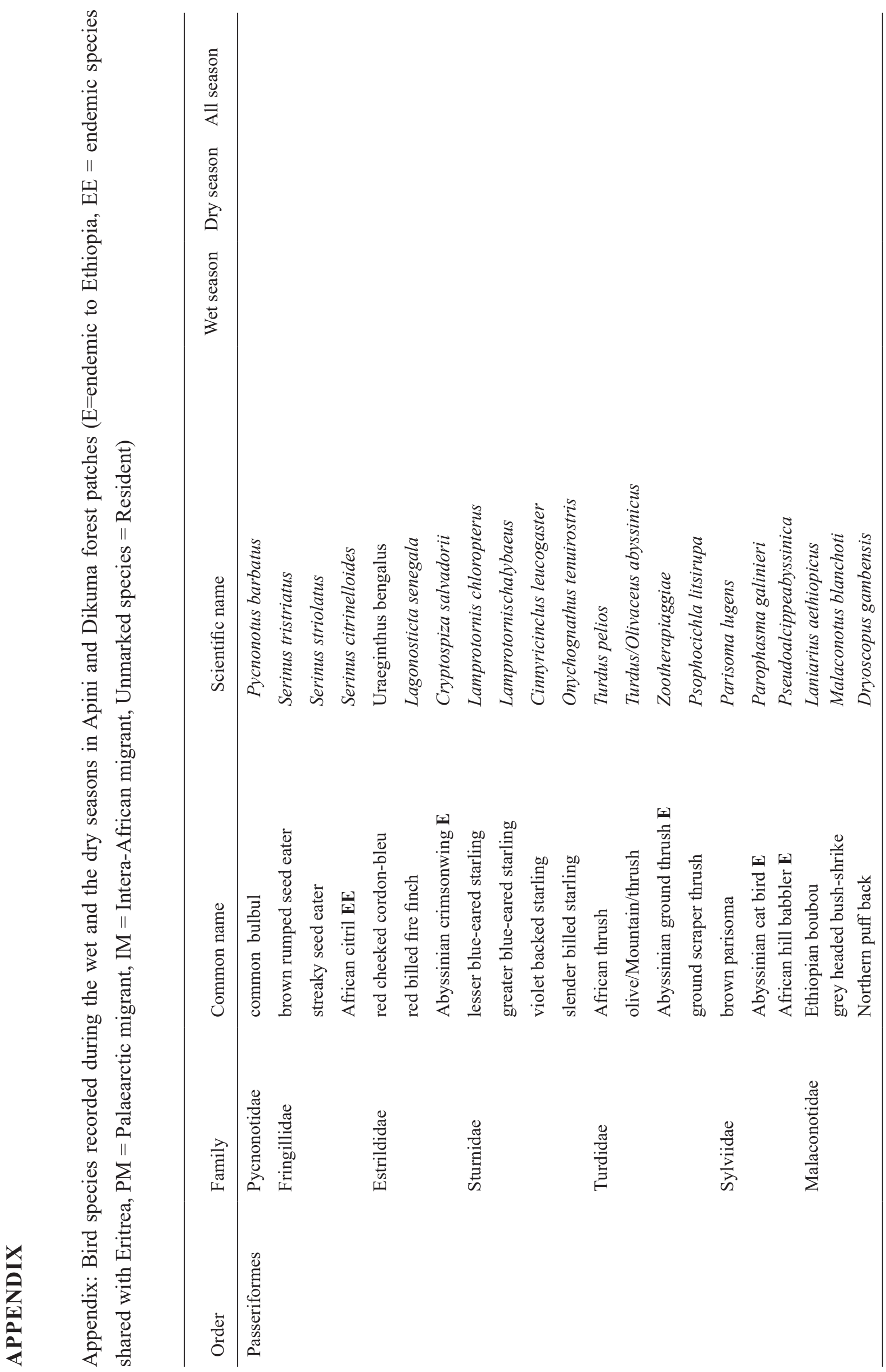




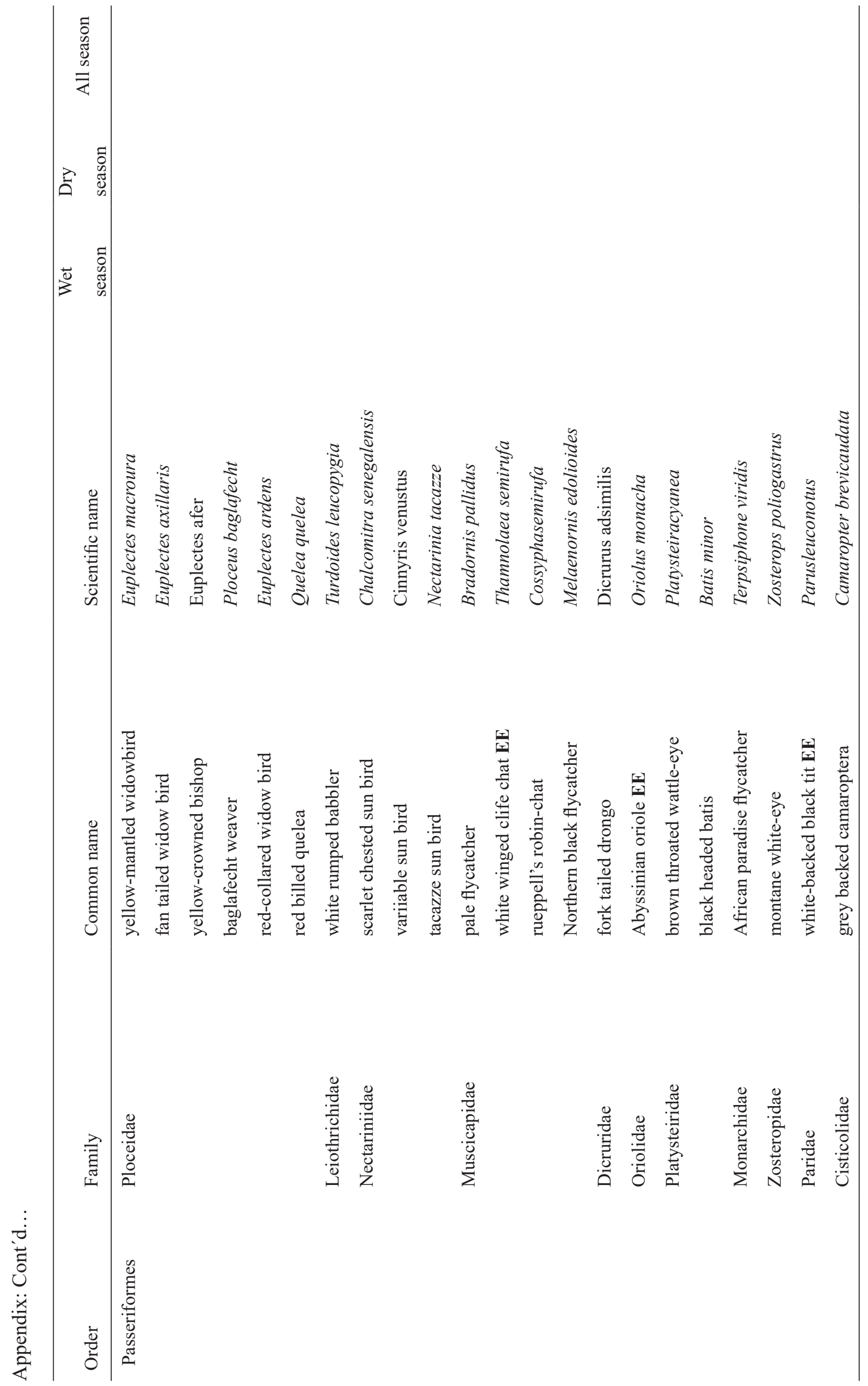




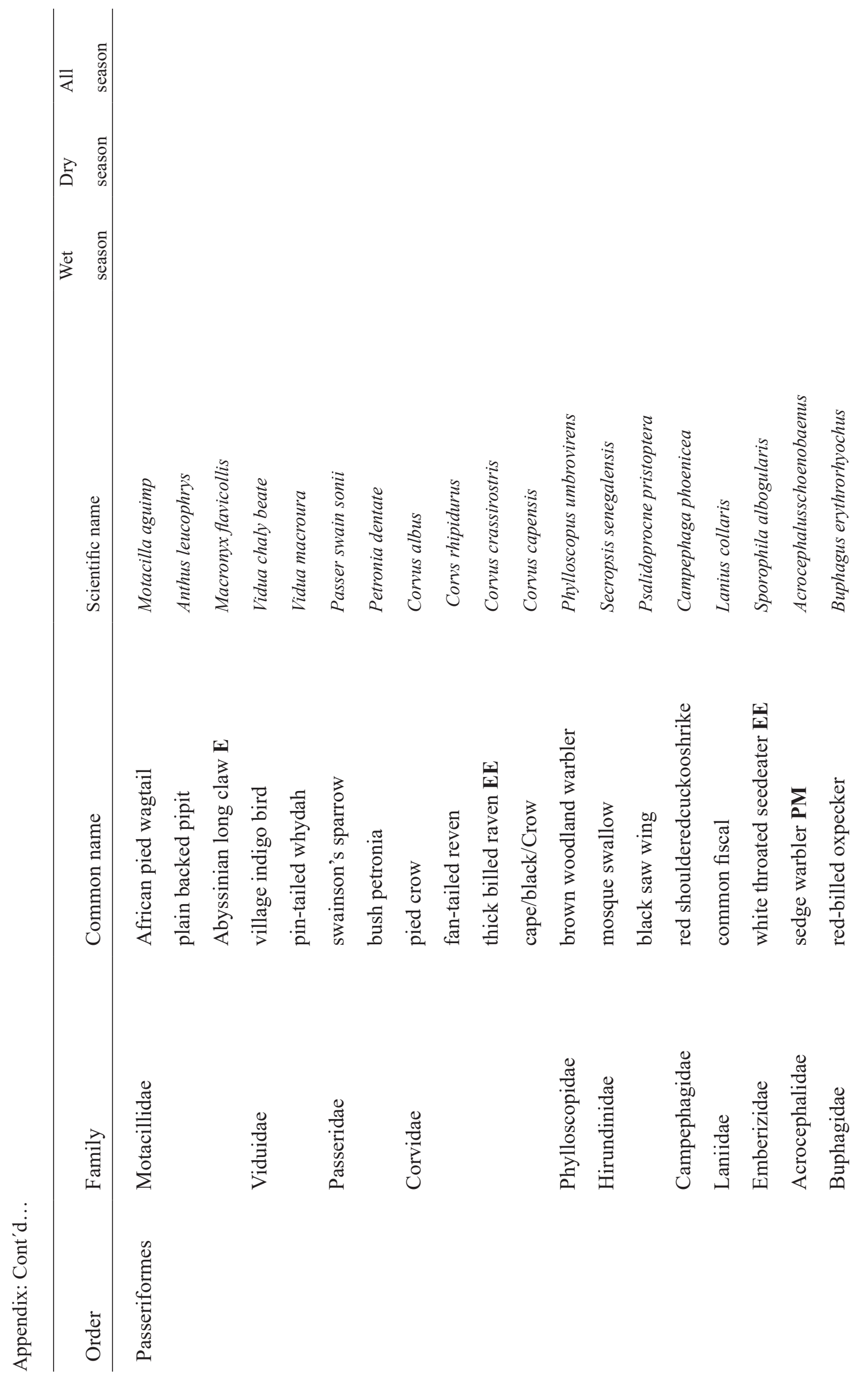




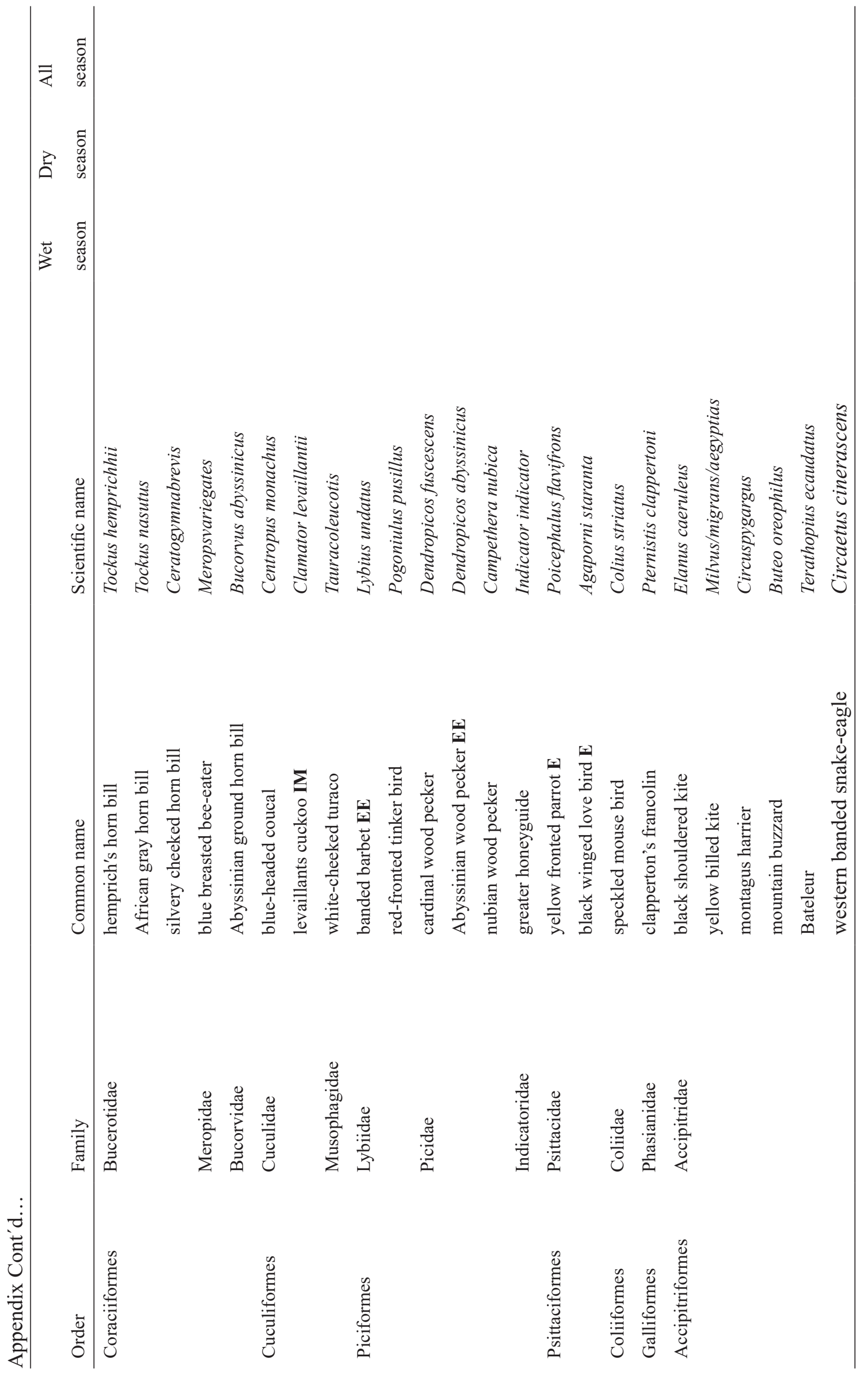




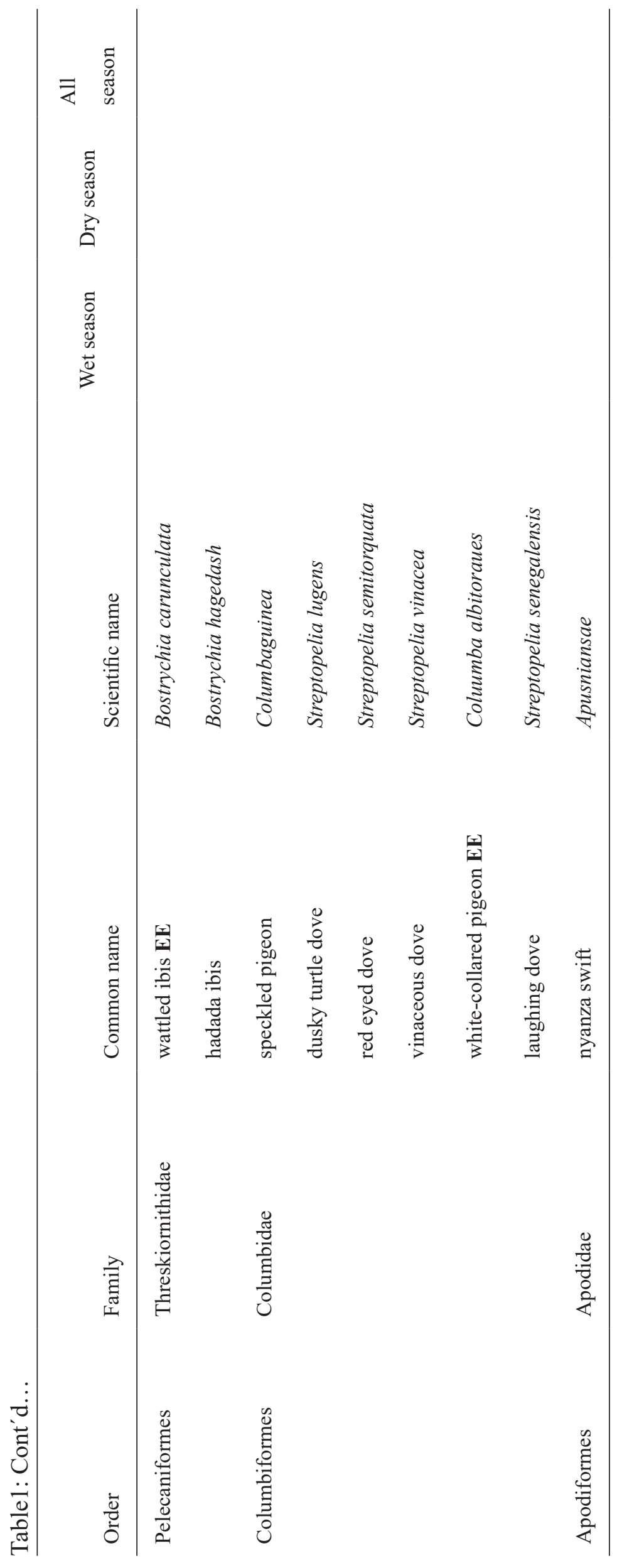

